\title{
A Study to Identify the Factors Influencing Quality of Life in Patients With Pulmonary Tuberculosis and to Develop A Self Instructional Module to Enhance the Quality of Life of Patients with Pulmonary Tuberculosis in Selected Dots Centres of Delhi
}

\author{
Shabana Khatun \\ Lecturer, Medical- Surgical Nursing, College of Nursing, SGPGIMS, Lucknow : 226014, UP.
}

\begin{abstract}
Background: TB is global. The WHO estimates that two billion people - one third of the world's population - are infected with Mycobacterium tuberculosis, the bacillus that causes the disease. Quality of life is an outcome measure worth considering for achieving a holistic approach measuring the impact of treatment to maximize the quality of life of the individual suffering from tuberculosis and also identify various factors which could have impact on quality of life due to disease condition and its treatment. In recent years, the evaluation of health related quality of life has emerged as an important and useful tool for studying the efficiency of medical therapies and not their benefits. Aim: 1. To assess the QOL. 2. To identify the factors influencing quality of life in patients with pulmonary tuberculosis. 3. To find the relationship of quality of life with following selected factors i.e age, sex, marital status, family, living room in a family, family member, family income, religion, locality, education status, occupation, ventilation, type of house, fuel for cooking, source of information, contracted TB, concurrent illness with TB. 4. To develop a self instructional module to enhance the quality of life of a patients with pulmonary tuberculosis. Material and methods: The research approach adopted for the study was, "descriptive survey" with "co- relational design." and conducted at DOTS centres of Delhi under the branch of MCD Chest Clinic, Nehru Nagar. Purposive sampling technique was employed to select the sample subjects. The sample size consisted of 100 patients. A structured interview schedule was used to identify the factors influencing QOL. Section I consisted of demographic data and section II identified factors which assess the quality of life, it include diagnosis issues, medication issues, social support and functioning, health behaviour, and accessibility of health provision. Results: The significant findings of the study were $26 \%$ of the pulmonary tuberculosis patients were in the level of best $Q O L, 61 \%$ were in the level of moderate quality of life and $13 \%$ of the pulmonary tuberculosis patients were in the level of poor quality of life. The mean QOL score was 94.1 and the standard deviation was 13.95. The mean percentage score of identified factors which affected QOL includes diagnosis issues (61.42\%), social support (61.47\%), health behaviour (70. 31\%) and medication issues (77.78\%) were in moderate quality of life and accessibility of health care provision (98.60\%) were in best quality of life of pulmonary tuberculosis patients. And SIM was developed and distributed to the patients. Conclusion: The findings showed that pulmonary tuberculosis had a substantial and encompassing impact on patients' quality of life. So developed self instructional module which provide health education to improve the quality of life of pulmonary tuberculosis patients.
\end{abstract}

Keywords: (QOL) Quality of life, pulmonary tuberculosis patients, identified factors

\section{Introduction}

Globally, it is estimated that 1.8 million people die from TB each year-the majority of them in developing countries. Tuberculosis (TB) remains a major public health problem in India. Revised National Tuberculosis Control Programme (RNTCP) uses the DOTS (Directly Observed Treatment, Short-course chemotherapy) strategy, which is based on results of tuberculosis research done in India.

WHO QoL (BREF), which has four domains, i.e. physical, psychological, social relationship and environmental, was used to assess the impact of pulmonary TB on the QoL. This study, therefore, had been aimed to know the impact quality of life and identify factors influencing QOL among pulmonary tuberculosis patients.

\section{Material and Methods}

The study was conducted at DOTS centres of Delhi under the branch of MCD Chest Clinic, Nehru Nagar (under that 3 DOTS centres: Balta House( Okhla) Jamia Ansari (Okhla) and Tejpur Pahari (Badarpur Border). Purposive sampling technique was employed to select the sample subjects. The sample size consisted of 100 pulmonary tuberculosis patients.

The research approach adopted for the study was, "descriptive survey" with "co- relational design". A structured interview schedule was used to identify the factors influencing QOL.

\section{Results}

The results presented into sections. 


\section{International Journal of Science and Research (IJSR) \\ ISSN (Online): 2319-7064}

Index Copernicus Value (2013): 6.14 | Impact Factor (2015): 6.391

Section I Description of sample characteristics. Majority of the sample subjects, i.e. $73 \%$ were males and the remaining $27 \%$ females. More than half of the sample subjects, i.e. $58 \%$ were married, $40 \%$ were unmarried and $2 \%$ were widow. More than half of the sample subjects, i.e. $54 \%$ belonged to joint family, (41\%) were from nuclear family and remaining 5\% were from extended family. More than half of the sample subjects, i.e. 53\% were Muslims, $46 \%$ were Hindus and remaining $1 \%$ was Christians. Majority of the sample subjects, i.e. $99 \%$ were from urban community and the remaining $1 \%$ was from rural community. Maximum of the sample subjects, i.e. $25 \%$ studied up to middle class, $23 \%$ studied up to primary, $23 \%$ studied up to high school, $16 \%$ studied up to intermediate, $10 \%$ studied up to graduation and remaining 3\% studied up to professional. Maximum of the sample subjects, i.e. $39 \%$ were skilled workers, $36 \%$ were housewives, $15 \%$ were unskilled workers, $3 \%$ were professional and remaining $7 \%$ were unemployed and students. Maximum of the sample subjects, i.e. $69 \%$ had 4 or above members in their family, $23 \%$ had 3 members, $6 \%$ had 2 members and remaining $2 \%$ had 1 member in their family. The majority of the sample subjects, i.e. $92 \%$ of pulmonary tuberculosis patients were living in pucca house and remaining $8 \%$ were living in semi - pucca house. Maximum of the sample subjects, i.e. $36 \%$ had 2 living rooms in their house, $27 \%$ had 3 living rooms, $25 \%$ had 1 room and remaining $12 \%$ had 4 or above rooms in their house. Majority of the sample subjects, i.e. $92 \%$ had proper ventilation in their house and remaining $8 \%$ had improper ventilation.

Majority of the sample subjects, i.e. $86 \%$ used gas for cooking and remaining $14 \%$ used kerosene oil. Maximum of sample subjects, i.e. $39 \%$ had family income of Rs. 20015000/-, 33\% earned Rs. 8001/- and above, 26\% earned Rs. 5001-8000/- and remaining $2 \%$ earned less than Rs. 2000/.Majority of the sample subjects, i.e. $85 \%$ found information about tuberculosis from health worker, $5 \%$ found it from community, $4 \%$ found the information from television, radio, books, newspaper, community, health worker, $4 \%$ found it from posters, $1 \%$ found it from television while remaining $1 \%$ found the information from books. Majority of the sample subjects, i.e. $81 \%$ were not aware from where they contracted tuberculosis, $15 \%$ had contracted tuberculosis from their family member, $2 \%$ contracted tuberculosis from community and remaining $2 \%$ had contracted tuberculosis from place of work. Majority of the sample subjects, i.e. $86 \%$ were not suffering from any concurrent illness, 3\% had arthritis, dribbling of urine, menstrual abnormality, 3\% had anaemia, 3\% had AIDS, $2 \%$ had diabetes, $2 \%$ had breathing problems and remaining $1 \%$ had heart disease

Section II Findings related to quality of life score. $26 \%$ of the pulmonary tuberculosis patients were in the level of best quality of life, $61 \%$ were in the level of moderate quality of life and $13 \%$ of the pulmonary tuberculosis patients were in the level of poor quality of life. The mean QOL score was 94.1, and standard deviation of QOL score was 13.95.

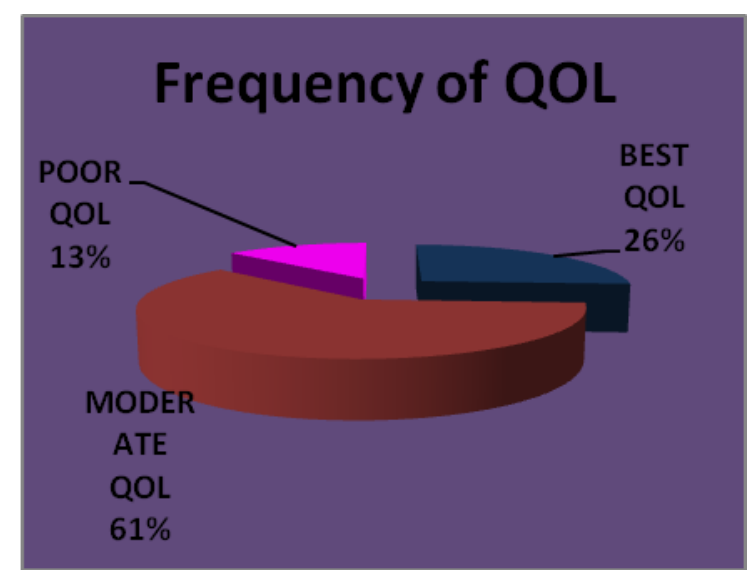

Figure 21: Pie diagram showing frequency distribution of the levels of QOL of pulmonary tuberculosis patients.

Section III Finding related to identify factors it includes diagnosis issues, medication issues, health behaviour, social support and accessibility of health care services. In diagnosis issues includes Symptoms, $50 \%$ of the sample subjects always experience weakness, $49 \%$ always experience low in energy, $44 \%$ always experience decreased appetite, $43 \%$ always experience breathlessness, $40 \%$ always experience cough, $25 \%$ always experience fever and $12 \%$ always experience blood in sputum.

Medication issues subdivided into adverse events, ease of administration of drugs and compliance. In adverse events $56 \%$ of the sample subjects always experience nausea, $32 \%$ always experience stomach pain, 29\% always experience joint pains, $4 \%$ always experience rashes and only $2 \%$ always experience dark rashes. Related to ease of administration in which $46 \%$ sample subjects always experience difficulty in swallowing, $38 \%$ always experience uneasiness, $21 \%$ are always scared of injection and $17 \%$ always need to crush tablets. Related to compliance in which 97\% sample subjects always experience red colour urine, 92\% always attended DOTS centre and 8\% sometimes attend DOTS centre because subjects had reasons like exams, attend funeral and visit of village.

In Social support and functioning, 54\% of the sample subjects always believe that TB is social stigma, $46 \%$ are always ashamed of diagnosis, $42 \%$ always not able to adjust with their family members, $27 \%$ believe that they are accepted by others, $20 \%$ always disclose their worries, $19 \%$ always dependent on others and $13 \%$ always attend social gathering.

Health behaviour subdivided into behaviour modification, attitude related to Tuberculosis and emotional impact. In behaviour modification in which $67 \%$ of the sample subjects have changed their lifestyle due to disease. $45 \%$ always had difficulty in climbing stairs, $44 \%$ always feel better after taking medication, $42 \%$ always find difficulty in walking, $19 \%$ always find difficulty in bathing and $6 \%$ always have difficulty in lifting small things. Regarding attitude $62 \%$ of the sample subjects said that TB spreads without taking precaution, $47 \%$ said that it requires sputum test during treatment, $38 \%$ said that TB is life threatening, $16 \%$ said that TB will reoccur after treatment, 5\% said that $\mathrm{TB}$ will completely cure and 5\% said that they will stop treatment 


\section{International Journal of Science and Research (IJSR) \\ ISSN (Online): 2319-7064 \\ Index Copernicus Value (2013): 6.14 | Impact Factor (2015): 6.391}

after symptoms subside. Related to emotional impact in which $46 \%$ of the sample subjects said that mental relaxation not possible, $42 \%$ always feel inferior as compared to others, $25 \%$ are always helpless regarding their disease condition and $19 \%$ always feel that they will die due to disease condition.

In Accessibility of health care provision, $100 \%$ of the sample subjects expressed that they had no difficulty in getting services at DOTS centre and $94 \%$ always agree that health provider visits their home and they are comfortable while communicating with health care provider.

The mean percentage score of identified factors which includes diagnosis issues $(61.42 \%)$, social support(61.47\%) and health behaviour(70. 31\%) and medication issues $(77.78 \%)$ were in moderate quality of life and accessibility of health care provision $(98.60 \%)$ were in best quality of life of pulmonary tuberculosis patients.

Section IV : there was no significant association was found in QOL scores of pulmonary tuberculosis patients with age, sex, family, educational status, occupation, income, family members, type of house, living rooms, kind of fuel, presence of concurrent illness.

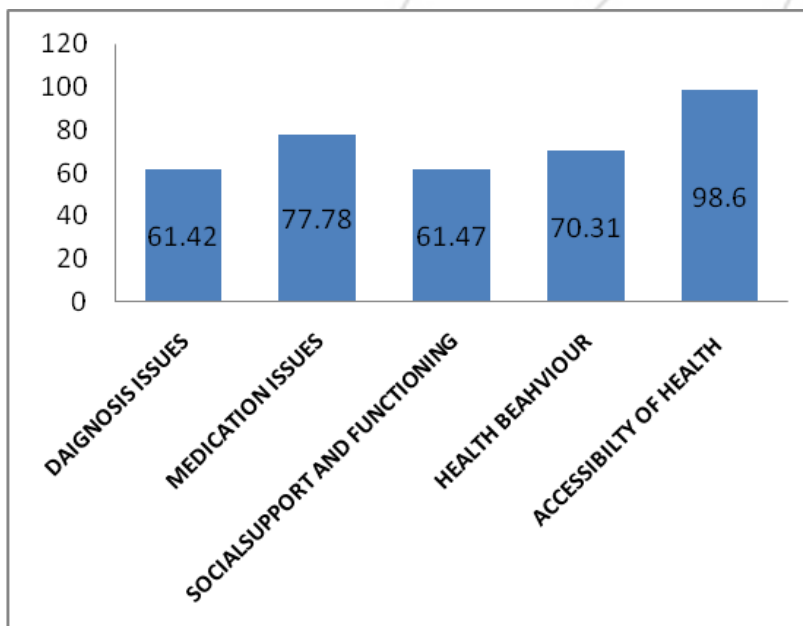

Figure 22: Bar diagram showing the mean percentage distribution of pulmonary tuberculosis patients by their identified factors being. However, TB patients' social functioning was also affected through isolation and the process of getting treatment for TB from the initial hospitalization to the daily medication schedules adversely affected the lives of participants.

Finally, both studies found impact on affected individuals QoL through issues related to its diagnosis, treatment, social support and functioning, and health behaviour.

However, there were some important differences between our two studies. In my study was quantitative study and closed ended question was asked by investigator. In my study I was assessed impact of QOL among patients and the identified factors which impact the QOL and significant relationship with selected factors has seen. Self instructional module developed to enhance the knowledge and improve QOL. But Marra CM study was qualitative and open ended question asked by investigator and only identified factors assessed.

\section{Conclusion}

My observation was despite the ability to cure TB, there remains a significant impact on QOL. Patients getting all the facilities of DOTS treatment under Revised National Tuberculosis Control Programme (RNTCP) but the factors i.e related to symptoms i.e under diagnosis issues, social support, health behaviour and medication compliance impaired QOL of pulmonary tuberculosis patients. But the accessibility of health care facilities doesn't impact on QOL. So investigator was developed a SIM which was based on identified factors to get adequate knowledge and improve QOL of pulmonary tuberculosis patients.

A declaration stating that "Factors influencing quality of life in patients with pulmonary tuberculosis is my original research work that has not been published and has not been sent for publication anywhere else."

\section{Authors' Undertaking}

Acknowledgement: not required, Funding: none from any source Informed consent: not required, Conflict of interest: none to declare, Ethical clearance: not required

Authors' contribution: (1)Mrs. Shabana khatun, Lecturer, CON, SGPGIMS, Lucknow, UP, India.

\section{References}

[1] Adriaanse H, Barnhoorn F. In search factors responsible for non compliance among tuberculosis patients in Wardha District. Social Science Medicine. October 1992; 4 (6): 291 -306.

[2] Aggarwal AN. Health-related quality of life: A neglected aspect of pulmonary tuberculosis. International journal of tuberculosis. January 2010;27(1):1-3.

[3] Aggarwal SP . New challenges in the implementation of RNTCP. Indian Journal of Tuberculosis. April 2005; 52(1): $1-4$

included those that are typically affected by most illnesses such as physical functioning and emotional/mental well- 


\section{International Journal of Science and Research (IJSR) \\ ISSN (Online): 2319-7064}

Index Copernicus Value (2013): 6.14 | Impact Factor (2015): 6.391

[4] Aggarwal SS. Assessment of one year of RNTCP. Indian journal of community medicine. July 2004; 29(4): 45.

[5] Amare D. Tuberculosis and HIV co-infection: its impact on quality of life.Health and Quality of Life Outcomes. December 2009; 7 (2): 105.

[6] Banu VV. Assessment of long term status of sputum positive pulmonary tuberculosis patients successfully treated with short course chemotherapy. Indian Journal of tuberculosis. April 2008; 56:132-140.

[7] Betty C. Quality of Life in Tuberculosis: A Review of the English Language Literature. Quality of Life Research. Dec 2004; 13(10):1633-1642.

[8] Byoung H L. Post-tuberculosis destroyed lung: Clinical characteristics and health-related quality of life measurement. Indian journal of tuberculosis. October 2007; 132(4): 639.

[9] Chamla D.The assessment of patients' health-related quality of life during tuberculosis treatment. International Journal of Tuberculosis and Lung Disease. April 2004;8:1100-1106.

[10]Chang JA. Assessment of Health-Related Quality of Life in Patients with Interstitial Lung Disease. International journal of tuberculosis.March 1999; 116:1175-1182.

[11] Miller TL. Personal and societal health quality lost to tuberculosis. International Journal of Tuberculosis. April 2009; 4(4): 508.

[12] Muniyandi M. Evaluation of post-treatment healthrelated quality of life (HRQOL) among tuberculosis patients. International Journal of Tuberculosis and Lung Diseases. August 2007;11:887-892

[13] National tuberculosis centre .2005. Staying on track with TB medicine.CDC.

\section{Author Profile}

Mrs. Shabana Khatun, RN RM is Lecturer, College of Nursing, SGPGIMS, Lucknow : 226014, UP. 